

\title{
Hypoglycaemia among adults with Type 2 Diabetes mellitus in a Family Medicine Clinic Sodipo $\mathrm{OO}^{* 1}$, Ademolu AB², Odunaye-Badmus S1, Oluwatuyi EO', Odiana $\mathbf{R}^{1}$
}

1Department of Family Medicine, Lagos State University Teaching Hospital, Ikeja, Lagos ${ }^{2}$ Department of Internal Medicine, Lagos State University Teaching Hospital, Ikeja, Lagos

*Correspondence: Dr OO Sodipo, Department of Family Medicine, Lagos State University Teaching Hospital, Ikeja, Lagos. E-mail: olujimiso@gmail.com; ORCID - https://orcid.org/0000-0002-5667-3656.

\begin{abstract}
Background: The prevalence of Diabetes mellitus (DM) is increasing worldwide. The complications of DM arising from hyperglycaemia are well documented and. However, there is a lack of data, poor awareness and information on hypoglycaemia in DM.

Objective: To describe the prevalence and factors associated with hypoglycaemia among patients with Type 2 Diabetes mellitus (DM).

Methods: This was a retrospective study of the clinical records of patients with Type 2 DM at the Family Medicine Clinic of a Nigerian teaching hospital from January 2019 to January 2020. The sociodemographic and clinical characteristics, including hypoglycaemia, Glycosylated Haemoglobin (HbA1c), Fasting and Random blood glucose, were retrieved.

Results: A total number of 570 patients were assessed, with a prevalence of $43(7.5 \%)$ of hypoglycaemia. The mean age of the patients in the study was 58.2 \pm 10.9 years (range: $36-83$ years). Metformin (557; 97.7\%), Sulphonylureas (377; $66.1 \%)$, Dipeptidylpeptidase -4 inhibitors $(137 ; 24.0 \%)$ and insulin $(72 ; 12.6 \%)$ were the most prescribed anti-diabetic medications. hypoglycaemiaA majority $(29 ; 67.4 \%)$ of the hypoglycaemia episodes occurred in the morning, while most $(24 ; 55.8 \%)$ of the episodes of hypoglycaemia were mild. Mean age $(t=2.35 ; p=0.019)$, presence of hypertension $\left(X^{2}=\right.$ $6.92, \mathrm{p}=0.008)$ and dyslipidaemia $\left(X^{2}=7.86, \mathrm{p}=0.005\right)$ were associated with hypoglycaemia.

Conclusions: The prevalence of hypoglycaemia in the Outpatient clinic was low, while the presence of comorbidities (hypertension and dyslipidaemia) and age were associated with hypoglycaemia. There is a need for patient education and Self-Monitoring of Blood Glucose (SMBG) to prevent complications of hypoglycaemia. hypoglycaemia
\end{abstract}

Keywords: Dipeptidylpeptidase-4 Inhibitors, Dyslipidaemia, Hypertension, Hypoglycaemia, Insulin, Sulphonylurea.

\section{Introduction}

The prevalence of Diabetes mellitus is increasing worldwide and in Africa, with the International Diabetes Federation (IDF) projecting that there will be an increase in persons with DM from 463 million in 2019 to 700 million by 2045. [1] The strict control of DM is increasingly emphasised following the benefits demonstrated in various studies, including the UK Prospective Diabetes Study (UKPDS) and The Diabetes Control and Complications Trial (DCCT) studies on 
preventing complications. ${ }^{[2,3]}$ Due to the shortage of endocrinologists in Nigeria and Africa, primary care physicians care for many Type 2 DM (T2DM) patients. Hypoglycaemia in T2DM patients in Outpatient settings has been documented in literature within and outside Nigeria. ${ }^{[4-7]}$

Hypoglycaemia is a medical emergency and a prevalent complication of intensive diabetes therapy. [8, 9] Randomized controlled trials, namely, the ADVANCE, [10] VADT, [11] and ACCORD, [12] studies revealed a three-fold increased risk of hypoglycaemic episodes while trying to maintain glycaemic goals. Although preventable, hypoglycaemic episodes, especially if severe or recurrent, may result in increased cardiovascular morbidity and mortality, significant psychosocial dysfunction, and reduced quality of life. ${ }^{[13,14]}$ A recent study in the United States found that nearly $76 \%$ of clinicians would treat their patients with diabetes more aggressively if not for concerns about inducing low blood sugar. [15] Unfortunately, the actual burden of DM in most centres is underestimated due to poor use of Self- monitoring of Blood Glucose, hence poor diagnosis, lack of knowledge on its implications and ultimately, poor treatment.

Whipple's triad most convincingly documents hypoglycaemia: symptoms consistent with hypoglycaemia, a low plasma glucose concentration at the time of the symptoms, and reversal of those symptoms when the plasma glucose concentration is corrected. [13] The American Diabetes Association (ADA) defined hypoglycaemia as blood glucose of less than or equal to $70 \mathrm{mg} / \mathrm{dl}$. [13] The American Diabetes Association (ADA)/ European Association for the Study of Diabetes (EASD) 2018 Classification of hypoglycaemia classifies hypoglycaemia as follows: [16]

a) Level 1: Glucose $=55 \mathrm{mg} / \mathrm{dl}$ $(3.0 \mathrm{mmol} / \mathrm{l})-70 \mathrm{mg} / \mathrm{dl}(3.6 \mathrm{mmol} / \mathrm{l})$ b) Level 2: Glucose $<55 \mathrm{mg} / \mathrm{dL} \quad(3.0$ $\mathrm{mmol} / \mathrm{L}$ )

c) Level 3: A severe event characterised by altered mental and physical status requiring assistance.

The ADA Work Group on T2DM also coined a term, "Probable Symptomatic Hypoglycaemia", where the exact value of the glucose levels need not be measured.[13] The reported prevalence of hypoglycaemia in a study in south-western Nigeria was $50 \%$, ${ }^{[17]}$ similar to the finding in a survey in South-eastern Nigeria, which reported a prevalence of $48 \%$. [7] They were both higher than the finding in a German prospective trial, which reported a hypoglycaemia prevalence of 14\%. [18] A study carried out in South-eastern Nigeria among patients with DM reported that knowledge of the causes, symptoms, and self-management practices for hypoglycaemia was inadequate. ${ }^{[4]}$ It is essential to examine the problem of hypoglycaemia to identify associated factors, including the timing. This study aimed to describe the prevalence and some of the factors associated with hypoglycaemia among patients with T2DM in a primary care clinic setting, with a view to further research on this commonly missed medical challenge.

\section{Methods}

\section{Study Area}

This study was carried out at the Chronic Medical Disorder (CMD) Clinic of the Family Medicine Department, Lagos State University Teaching Hospital, Ikeja, Lagos. The hospital is situated in the Southwestern part of Nigeria in Lagos State, and the centre serves as a training, research and referral centre in the state. The CMD Clinic enrols and manages patients with uncomplicated T2DM. The annual CMD Clinic attendance is about 4,000, with a monthly average of 100 patients and weekly attendance of 20-30 patients. Study Design: This was a retrospective study of the clinical records of patients with T2DM treated 
from January 2019 to January 2020, assessing for documented clinical or laboratory hypoglycaemia.

Study Population: It comprised 555 patients with T2DM who were on oral hypoglycaemic medications and received medical care at the CMD Clinic of the Lagos State University Teaching Hospital (LASUTH), Ikeja, Lagos State. Inclusion Criteria: Adult patients (18 years and above) with T2DM who were on oral hypoglycaemic medications and whose hospital records showed documented clinical features of hypoglycaemia and fasting and random blood glucose values.

Exclusion Criteria: Patients without the required clinical information and those diagnosed with Type 1 DM, Gestational DM or secondary DM.

Data Collection and Procedure: At presentation at the clinic, the blood pressure, fasting blood glucose or random blood glucose readings are routinely measured. The blood glucose readings from Self-Monitoring of Blood Glucose (SMBG) of patients who practice it are also reviewed and recorded. Clinical records of blood glucose levels and symptoms among diabetic patients are also studied in the clinic. Blood glucose is obtained at each visit while glycosylated haemoglobin (HbA1c) is assayed every 3-6 months.

In the present study, the sociodemographic characteristics of patients were also retrieved from the records. The clinical characteristics, including the details of oral hypoglycaemic medications used, clinical features of hypoglycaemia, co-morbid conditions, were recorded. Similarly, the Self-Monitoring of Blood Glucose (SMBG) records were examined for patients who used that method of care.

\section{Definition of Outcome Variables}

Hypoglycaemia was defined as Fasting or Random blood glucose below 70mg/dl. [13] The severity was further classified as mild (55$70 \mathrm{mg} / \mathrm{dl})$ and severe $(<55 \mathrm{mg} / \mathrm{dl})$. [13]
Hypertension was defined as systolic blood pressure $\geq 140 \mathrm{mmHg}$ and or diastolic blood pressure $\geq 90 \mathrm{mmHg}$ or use of anti-hypertensive medications.

Dyslipidaemia was defined as Total Cholesterol $\geq 200 \mathrm{mg} / \mathrm{dl}, \mathrm{HDL}<40 \mathrm{mg} / \mathrm{dl}$, Triglyceride $\geq$ $150 \mathrm{mg} / \mathrm{dl}$ and LDL $\geq 150 \mathrm{mg} / \mathrm{dl}$ or use of antilipid drugs.

Obesity was defined as Body mass index (BMI) $\geq$ $30 \mathrm{~kg} / \mathrm{mg}^{2}$.

Glycaemic control was described as "good" with glycosylated haemoglobin (HbA1c) $\leq 7 \%$ or "poor" with $\mathrm{HbA} 1 \mathrm{c}>7 \%$.

Ethical Approval: Approval was granted by the Health and Research Ethics Committee of LASUTH with approval number LREC/06/10/1491. The personal details of the patients were used in a non-identifiable and confidential manner.

Data analysis: Data were analysed using Epi Info 7, Centre for Disease Control (CDC). Percentages, means and standard deviations of numerical variables were determined. Categorical variables were compared using the Chi-Square test with Fisher's Exact test applied where cells had numbers less than 5. Continuous variables were compared using the Student's t-test. Statistical significance was defined by a $p$-value $<0.05$.

\section{Results}

A total of 570 patients with T2DM were studied, with about half $(269 ; 47.2 \%)$ being older $(\geq 60$ years). The mean age of the patients was $58.2 \pm 10.9$ years. Close to two-thirds of the patients $(366 ; 64.2 \%)$ were females. Close to twothirds $(363 ; 63.7 \%)$ were on two or more oral hypoglycaemics. Overall, 257 (45.1\%) had poor glycaemic control. Most of the patients had comorbidities; 350 (61.4\%) were hypertensive, 281 (49.3\%) had dyslipidaemia, and 110 (19.3\%) were obese, as shown in Table I. About one-tenth 
(43; $7.5 \%)$ of the patients had hypoglycaemia with severe hypoglycaemia in about one fifth $(9 / 43$; $20.9 \%$ ), as shown in Table I.

Metformin (557; 97.7\%), sulphonylureas (377; $66.1 \%)$, dipeptidylpeptidase -4 inhibitors (137; $24.0 \%)$ and insulin $(72 ; 12.6 \%)$ were the most prescribed oral hypoglycaemic medications as shown in Table II. Most of the cases of hypoglycaemia $(28 ; 65.1 \%)$ occurred in the morning, while a third $(13 ; 30.2 \%)$ occurred in the afternoon. A case each $(2.3 \%)$ was recorded at night and midnight.

The mean age of the patients with hypoglycaemia was significantly higher, $61.9 \pm 11.7$ years vs $57.9 \pm 10.8$ years $(t=2.35, p=0.019)$. The average number of oral hypoglycaemics received by patients with and without hypoglycaemia was similar $(1.9 \pm 0.3$ vs $1.9 \pm 0.5 ; \mathrm{t}=0.05, \mathrm{p}=0.96)$. Although patients with hypoglycaemia had a longer duration of illness, the difference lacked statistical significance $(7.0 \pm 6.2$ years vs $6.1 \pm 6.1$ years; $\mathrm{t}=0.93, \mathrm{p}=0.35$ ). In addition, the mean HbA1c was higher among those without hypoglycaemia but without statistical significance $(8.5 \pm 2.6 \%$ vs $7.7 \pm 2.3 \% ; t=1.72, p=$ 0.06). The presence of hypertension and dyslipidaemia were significantly associated with the occurrence of hypoglycaemia $(p=0.008$ and 0.005 , respectively), as shown in Table III.

\section{Discussion}

This retrospective audit of patients with T2DM attending a primary care setting may assist with drawing attention to the burden of hypoglycaemia at the primary care level. The audit found the prevalence of hypoglycaemia as $7.5 \%$. This is far lower than other studies in Nigeria reported, with figures ranging from $50 \%$ in southwest Nigeria [17] to $48 \%$ in southeast Nigeria ${ }^{[7]}$ and $41.2 \%$ in Benin, southern Nigeria.
[8] The prevalence in the present study is closer to the finding in a German prospective trial, which reported a prevalence of $14 \%$. [18] The lower rate reported from the present study may be due to the results of SMBG, which were not recorded during clinic visits.

The preponderance of females in the present study is in keeping with the findings in other studies in Nigeria [17,18] and India [19], suggesting that females use health care facilities more than males. However, there was no significant association between gender and hypoglycaemia in this study. There was also a preponderance of elderly patients in the present study as the mean age of the participants was 60.7 years, similar to the findings in other studies. [8,17-19] Advanced age may likely be significantly associated with hypoglycaemia in this study. This group of patients can have severe consequences from falls arising from hypoglycaemia, including fractures, amongst other complications. It was also noted that about half of the participants received antineuropathy drugs. Autonomic dysfunction affects awareness and response to hypoglycaemia. Therefore, this condition predisposes to severe forms of hypoglycaemia. [4,12]

The risk factors for hypoglycaemia in T2DM, in addition to medications, include physical exercises, advanced age, presence of comorbidities, lack of awareness of features of hypoglycaemia, excessive dieting or weight loss, alcohol, long duration of the illness and long duration of insulin use. $[8,13,20-, 22]$ The association of hypoglycaemia with age and comorbidities such as hypertension and dyslipidaemia as found in the present study agrees with the findings in a southwest Nigeria study which reported that older age, longer duration of diabetes illness, possession of a glucometer and use of insulin were associated with higher odds of hypoglycaemia. ${ }^{[17]}$ 
Table 1: Sociodemographic and clinical characteristics of the participants

\begin{tabular}{|c|c|c|}
\hline Variable & Frequency $(\mathrm{N})$ & Percentage (\%) \\
\hline \multicolumn{3}{|c|}{ Age (Year) $(N=570)$} \\
\hline $21-29$ & 03 & 0.6 \\
\hline $30-39$ & 28 & 4.9 \\
\hline $40-49$ & 77 & 13.5 \\
\hline $50-59$ & 193 & 33.8 \\
\hline $60-69$ & 184 & 32.3 \\
\hline$>70$ & 85 & 14.9 \\
\hline \multicolumn{3}{|c|}{ Gender $(N=570)$} \\
\hline Male & 204 & 35.8 \\
\hline Female & 366 & 64.2 \\
\hline \multicolumn{3}{|c|}{ Ethnic Group $(N=570)$} \\
\hline Yoruba & 304 & 53.3 \\
\hline Ibo & 149 & 26.1 \\
\hline Others & 108 & 18.9 \\
\hline Hausa & 09 & 1.6 \\
\hline \multicolumn{3}{|c|}{ Current Smoking (N = 570) } \\
\hline No & 548 & 96.1 \\
\hline Yes & 22 & 3.9 \\
\hline \multicolumn{3}{|c|}{ Use of Alcohol $(\mathrm{N}=570)$} \\
\hline No & 480 & 84.2 \\
\hline Yes & 90 & 15.8 \\
\hline \multicolumn{3}{|c|}{ History of Hypertension $(N=570)$} \\
\hline No & 218 & 38.2 \\
\hline Yes & 352 & 61.7 \\
\hline \multicolumn{3}{|c|}{ Dyslipidaemia (N = 570) } \\
\hline No & 289 & 50.7 \\
\hline Yes & 281 & 49.3 \\
\hline \multicolumn{3}{|c|}{ Obesity ( $N=278$ ) } \\
\hline No & 168 & 60.4 \\
\hline Yes & 110 & 39.6 \\
\hline
\end{tabular}

This study noted that only about a quarter of the patients had clinical symptoms, hence the importance of glucometers in monitoring highrisk patients. A study in China reported that episodes of hypoglycaemia occurred at various times, including before meals in the morning, mid-day, and night. [23]. However, a study design that checked glucose levels multiple times in the day was used in that Chinese study.[23] Other studies have reported different high-risk periods such as the night, before lunch and before going to bed, [24] night and after each meal, ${ }^{[25]}$ or before lunch, [26] as the highest risk times for the occurrence of hypoglycaemia. 
Table I1: Details of diabetic illness, medications and occurrence of hypoglycaemia

\begin{tabular}{|c|c|c|}
\hline Variable & Frequency $(N)$ & Percentage (\%) \\
\hline \multicolumn{3}{|c|}{$\begin{array}{l}\text { Duration of Diabetic Illness (Years) } \\
(\mathrm{N}=570)\end{array}$} \\
\hline $0-5$ & 355 & 62.3 \\
\hline $6-10$ & 104 & 18.3 \\
\hline $11-15$ & 55 & 9.6 \\
\hline$>15$ & 56 & 9.8 \\
\hline \multicolumn{3}{|l|}{ Mean- $8.47 \pm 2.67$} \\
\hline \multicolumn{3}{|c|}{$\begin{array}{l}\text { Number of anti-diabetic Drugs } \\
(N=570)\end{array}$} \\
\hline 1 & 114 & 20.0 \\
\hline 2 & 363 & 63.7 \\
\hline 3 & 62 & 10.9 \\
\hline More than 3 & 31 & 5.4 \\
\hline Mean- $1.96 \pm 0.57$ & & \\
\hline \multicolumn{3}{|l|}{ Types of Drugs $*(N=570)$} \\
\hline Metformin & 557 & 97.7 \\
\hline Sulphonylurea & 377 & 66.1 \\
\hline DPP-4 & 137 & 24.0 \\
\hline Insulin & 72 & 12.6 \\
\hline SGLT-2 & 9 & 1.6 \\
\hline a glucosidase inhibitors & 5 & 0.9 \\
\hline \multicolumn{3}{|c|}{$\begin{array}{l}\text { Glycaemic Control (HbA1c) } \\
\text { (N-377) }\end{array}$} \\
\hline$\leq 7 \%$ & 122 & 32.4 \\
\hline$>7 \%$ & 255 & 67.6 \\
\hline \multicolumn{3}{|l|}{ Mean $\mathrm{HbA} 1 \mathrm{c} 8.47 \pm 2.67$} \\
\hline \multicolumn{3}{|l|}{ Hypoglycaemia $(N=570)$} \\
\hline No & 527 & 92.5 \\
\hline Yes & 43 & 7.5 \\
\hline \multicolumn{3}{|c|}{$\begin{array}{l}\text { Severity of Hypoglycaemia } \\
(N=43)\end{array}$} \\
\hline Severe & 09 & 20.9 \\
\hline Not severe & 34 & 79.1 \\
\hline
\end{tabular}

*- Multiple responses

Another Nigerian study reported that $28.3 \%$ of hypoglycaemic episodes occurred in the afternoon, before lunch but least occurred at night. [17] These differences may be due to the different methods used to report the occurrence of hypoglycaemia. It could also be affected by the practice of self-monitoring blood glucose. The present study found that the highest risk of hypoglycaemia was in the morning and afternoon. This could be because most of the data were obtained from clinical records of patients who checked their blood glucose levels in the clinics. Studies have indicated that hypoglycaemia or severe hypoglycaemia can occur in a percentage of patients taking insulin therapy, [27] or metformin and sulfonylurea combination. [27-30] Shiraam et al., [31] also reported that the combination therapy of sulfonylurea with metformin was the most frequently used therapy for patients with T2DM who suffered hypoglycaemic coma. 
Table III: Relationship between sociodemographic and clinical factors and hypoglycaemia

\begin{tabular}{|c|c|c|c|c|}
\hline Variable & $\begin{array}{l}\text { Hypoglycaemia } \\
\text { Absent }\end{array}$ & $\begin{array}{l}\text { Hypoglycaemia } \\
\text { Present }\end{array}$ & Statistics & p-value \\
\hline Mean Age (years)* & $57.9 \pm 10.85$ & $61.98 \pm 11.7$ & 2.35 & 0.019 \\
\hline \multicolumn{5}{|l|}{ Gender } \\
\hline Male $(n=204)$ & 187 (91.7) & $17(8.3)$ & 0.27 & 0.60 \\
\hline Female $(n=365)$ & 339 (92.9) & $26(7.1)$ & & \\
\hline \multicolumn{5}{|l|}{ Presence of Hypertension } \\
\hline \multirow{2}{*}{$\begin{array}{l}\text { No }(n=214) \\
\text { Yes }(n=349)\end{array}$} & $206(96.3)$ & $8(3.7)$ & 6.92 & 0.008 \\
\hline & $315(90.3)$ & $34(9.7)$ & & \\
\hline Presence & & & & \\
\hline \multicolumn{5}{|l|}{ Dyslipidaemia } \\
\hline No $(n=289)$ & 276 (95.5) & $13(4.5)$ & 7.86 & 0.005 \\
\hline Yes $(n=280)$ & $250(89.3)$ & 30 (10.7) & & \\
\hline \multicolumn{5}{|l|}{ Use of Alcohol** } \\
\hline No $(\mathrm{n}=488)$ & $449(92.0)$ & $39(8.0)$ & 1.74 & 0.18 \\
\hline Yes $(n=79)$ & $76(96.2)$ & $3(3.8)$ & & \\
\hline \multicolumn{5}{|l|}{ Obesity } \\
\hline No $(n=168)$ & 154 (91.6) & $14(8.4)$ & 0.23 & 0.31 \\
\hline Yes $(n=110)$ & $99(90.0)$ & $11(10.0)$ & & \\
\hline \multicolumn{5}{|l|}{ Mean number of Drugs* } \\
\hline & $1.9 \pm 0.56$ & $1.9 \pm 0.37$ & 0.05 & 0.96 \\
\hline \multicolumn{5}{|l|}{ Mean duration of } \\
\hline Diabetic Illness (Years)* & $6.15 \pm 6.16$ & $7.07 \pm 6.22$ & 0.93 & 0.35 \\
\hline Mean $\mathrm{HbA1c}(\%)^{*}$ & $8.54 \pm 2.69$ & $7.72 \pm 2.35$ & 1.72 & 0.06 \\
\hline \multicolumn{5}{|l|}{ Sulphonylurea use } \\
\hline No $(n=195)$ & $182(93.3)$ & $13(6.7)$ & & \\
\hline Yes $(n=364)$ & $334(91.8)$ & $30(8.2)$ & 0.34 & 0.56 \\
\hline \multicolumn{5}{|l|}{ DPP-4 Inhibitors use } \\
\hline No $(n=432)$ & 398 (92.1) & $34(7.9)$ & & \\
\hline Yes $(n=137)$ & $128(93.4)$ & $9(6.6)$ & 0.25 & 0.62 \\
\hline \multicolumn{5}{|l|}{ Metformin use } \\
\hline No $(n=13)$ & $12(92.3)$ & $1(7.7)$ & & \\
\hline Yes $(n=556)$ & $514(92.4)$ & $42(7.6)$ & 0.26 & 0.65 \\
\hline \multicolumn{5}{|l|}{ Insulin use } \\
\hline No $(n=496)$ & 460 (92.7) & $36(7.3)$ & & \\
\hline Yes $(n=99)$ & $66(66.7)$ & $33(33.3)$ & 0.10 & 0.744 \\
\hline
\end{tabular}

\footnotetext{
* Student's t-test, ${ }^{* *}$ Fishers Exact; Some data are missing.
}

The findings in the present study showed that metformin, sulphonylurea and insulin were the most commonly used oral hypoglycaemics. The use of newer oral hypoglycaemic drugs such as the DPP4- Inhibitors, Sodium-Glucose
Transporter 2 Inhibitors have been reported to have lower incidences of hypoglycaemia as compared to sulfonylureas. [32,33] However, the present study found no significant association 
between the types of oral hypoglycaemic drugs and hypoglycaemia.

The prescription of insulin at primary care is increasing, and about $10 \%$ of the patients in the present study were receiving insulin. This could lead to an increased risk of hypoglycaemia at this level of care, especially if SMBG is not correctly implemented. Long action or premixed insulin has a reduced risk of hypoglycaemia compared to multiple doses of rapid-acting insulin. [34] It remains a good option of care at the primary care level. It is essential to educate diabetic patients on the prevention, symptoms, diagnosis and treatment of hypoglycaemia, including how their diet affects their glucose levels. [35]

Limitations: The retrospective nature of this study allowed cases of incomplete documentation and missing data. Specific risk factors for hypoglycaemia in T2DM, such as exercise, autonomic dysfunction, dietary inadequacy, weight loss, alcohol use, and type of insulin used, could not be assessed in the present study.

\section{Conclusions}

The observed low prevalence of hypoglycaemia may be due to the study's retrospective design. However, there is a need for patient education and the use of SMBG to prevent complications, whilst physicians must ensure thorough review of SMBG records and proper documentation during clinical visits.

Acknowledgement: The consultants, residents and staff of the Family Medicine Department, LASUTH, Ikeja are appreciated. Rasheedat Tonade is also appreciated for helping with data collection and cleaning.

Authors' Contributions: $\mathrm{SOO}$ and $\mathrm{AAB}$ conceived the study, reviewed the literature, and drafted the manuscript. O-BS, OEO and OR did data collection,
SOO and OEO analysed the data while SOO, O-BS, and OR interpreted the data. SOO revised the manuscript for sound intellectual content. All the authors approved the final version of the manuscript.

Conflicts of Interest: None.

Funding: Self-funded.

Publication History: Submitted 12 May 2021; Accepted 12 November 2021.

\section{References}

1. International Diabetes Federation. IDF Diabetes Atlas, 9th Edition. Brussels, Belgium: 2019. Available at: http://www.diabetesatlas.org/ Accessed on 20 December 2020.

2. Parati G, Bilo G, Ochoa JE. Benefits of tight blood pressure control in diabetic patients with hypertension. Diabetes Care. 2011; 34: S297S303.https://doi.org/10.2337/dc11-s243

3. Fullerton B, Jeitler K, Seitz M, Horvath K, Berghold A, Siebenhofer A. Intensive glucose control versus conventional glucose control for type 1 diabetes mellitus. Cochrane Database of Systematic Reviews 2014, Issue 2. Art. No.: CD009122.

https://doi.org/10.1002/14651858.CD009122.p $\underline{\mathrm{ub} 2}$

4. Iloh GU, Amadi AN. Epidemiology of hypoglycaemia among ambulatory Type 2 diabetic patients in a primary care clinic of a tertiary hospital in Southeastern Nigeria. J Health Res Rev 2018; 5: 57-65. https://doi.org/10.4103/jhrr.jhrr_37_17

5. Birabwa C., Bwambale MF, Waiswa P. Quality and barriers of outpatient diabetes care in rural health facilities in Uganda - a mixed-methods study. BMC Health Serv Res .2019; 19 : 706 . https://doi.org/10.1186/s12913-019-4535-x

6. Ejegi A, Ross AJ, Naidoo K. Knowledge of symptoms and self-management of hypoglycaemia amongst patients attending a 
diabetic clinic at a regional hospital in KwaZulu-Natal. Afr J Pry Health Care Fam Med 2016; 8: e1-e6. https://doi.org/10.4102/phcfm.v8i1.906

7. Idowu $\mathrm{AO}$, Adesegun $\mathrm{OA}$, Osonuga $\mathrm{A}$, Osibowale B, Ajiro T, Ngubor TD, et al. Patterns and Impact of Consultations to an Endocrinology Unit in a Tertiary Hospital in Southwestern Nigeria. Niger Med J 2018; 59: 28-32.

https://doi.org/10.4103/nmj.NMI_167_18

8. Abisoye OA, Oseribhor U. Prevalence and Presentation of Diabetes-Related Hypoglycaemia amongst Persons with Diabetes in a Tertiary Health Institution in Nigeria. Int J Diabetes Endocrinol. Special Issue: Hypoglycemia in Diabetes 2020; 5: 3440 .

https://doi.org/10.11648/j.ijde.20200503.11

9. Besen BD, Arda Sürücü H, Kosar C. Self-reported frequency, severity of, and awareness of hypoglycemia in type diabetes patients in Turkey. Peer J 2016; 4: e2700. https://doi.org/10.7717/peerj.2700

10. Patel A, MacMahon S, Chalmers J. Intensive blood glucose control and vascular outcomes in patients with type 2 diabetes. $\mathrm{N}$ Engl J Med 2008; 358: 2560-2572.

11. Duckworth W, Abraira C, Moritz T. VADT Investigators. Glucose control and vascular complications in veterans with type 2 diabetes. N Engl J Med 2009; 360: 129-139.

12. Gerstein HC, Miller ME. Action to Control Cardiovascular Risk in Diabetes Study Group. Effects of intensive glucose lowering in type 2 diabetes. N Engl J Med. 2008; 358: 2545-2559.

13. American Diabetes Association Workgroup on Hypoglycemia. Defining and Reporting Hypoglycemia in Diabetes: A report from the American Diabetes Association Workgroup of Hypoglycemia. Diabetes Care. 2005; 5: 1245-1249.
14. Ratzki-Leewing A, Harris SB, Mequanint S. Real-world crude incidence of hypoglycemia in adults with diabetes: Results of the In Hypo-DM Study, Canada. BMJ Open Diab Res Care 2018; 6: e000503. https://doi.org/10.1136/ bmjdrc-2017000503

15. Leiter L, Yale J, Chiasson J. Assessment of the impact of fear of hypoglycemic episodes on glycemic and hypoglycemia management. Diabetes 2005; 29: 186-192.

16. International Hypoglycaemia Study Group: Glucose concentrations of less than $3.0 \mathrm{mmol} / \mathrm{L}$ ( $54 \mathrm{mg} / \mathrm{dL}$ ) should be reported in clinical trials: a joint position statement of the American Diabetes Association and the European Association for the Study of Diabetes. Diabetes Care 2017; 40: 155-157. https://doi.org/10.2337/dc16-2215

17. Olamoyegun MA, Ayodele AO, Enikuomehin AC, Akinlade AT. Incidence and Determinants of Reported Hypoglycaemia among Patients with Type 2 Diabetes Mellitus in a Tertiary Health Institution in Nigeria. J Diabetes Mellitus 2020: 10; 51-63.

18. Schope D, Bramlage P, Binz C, Krekler M, Deeg E, Gitt AK. Incidence and predictors of hypoglycaemia in type 2 diabetes. An analysis of the prospective DiaRegis registry. BMC Endocr Disord 2012; 12: 23-30. https://doi.org/https://doi.org/10.1186/14 $\underline{72-6823-12-23}$

19. Samya V, Shriraam V, Jasmine A, et al. Prevalence of Hypoglycemia among patients with Type 2 Diabetes Mellitus in a Rural Health Center in South India. J Prim Care Community Health 2019; 10: 2150132719880638. https://doi.org/10.1177/2150132719880638

20. Quilliam BJ, Simeone JC, Ozbay AB, Kogut SJ. The incidence and costs of hypoglycemia 
in type 2 diabetes. Am J Manag Care. 2011; 17: 673-680.

21. Parsaik AK, Carter RE, Pattan V, Myers LA, Kumar H, Smith SA, et al. Populationbased study of severe hypoglycemia requiring emergency medical service assistance reveals unique findings. J Diabetes Sci Technol 2012; 6: 65-73. https://doi.org/10.1177/19322968120060010 $\underline{9}$

22. Hsu PF, Sung SH, Cheng HM, Yeh JS, Liu WL, Chan WL, et al. Association of clinical symptomatic hypoglycemia with cardiovascular events and total mortality in type 2 diabetes: a nationwide populationbased study. Diabetes Care 2013; 36: 894-900. https://doi.org/10.2337/dc12-0916

23. Yang CM, Ma YL, Kang J , Jia Z, Wang YY. Time and department distribution of hypoglycemia occurrences in hospitalised diabetic patients. Int J Nurs Serv 2015: 9: $263-$ 267.

https://doi.org/10.1016/j.ijnss.2015.08.001

24. Shen LL, Zhang N. The situation analysis and nursing countermeasures of hypoglycaemia in hospitalised patients with diabetes. J Nurs 2012; $\quad$ 19(3A): 50e1. https://doi.org/10.1016/i.ijnss.2012.08.001

25. Ouyang SY, Wang QL, Wu XY. Hypoglycemia incidence survey hospitalised patients with diabetes. West China Med 2012; 27: 727e8.

26. Li DX, Song BY, Zhang LI, Ren L, Niu HY, Zhang H. 62 cases of type 2 diabetes patients in the intensive treatment characteristics analysis of hypoglycemia occurs. Chin J Nurs 2007; 42: 725e6.

27. Miller ME, Bonds DE, Gerslein HC, Seaquist ER, Bergenstal RM, Calles-Escandon J, et al. The effects of baseline characteristics, glycaemia treatment approach, and glycated haemoglobin concentration on the risk of severe hypoglycaemia: post hoc epidemiological analysis of the ACCORD study. BMJ 2010; 340: 5444. https://doi.org/10.1136/bmj.b5444

28. Wong MG, Petkovic V, Chalmers J, Woodward M, Li Q, Cooper ME, et al. Long-term benefits of intensive glucose control for preventing end-stage kidney disease: ADVANCE-ON. Diabetes Care 2016; 39: 694-700. https://doi.org/10.2337/dc15$\underline{2322}$

29. Agarwal AA, Jadhav PR, Deshmukh YA. Prescribing pattern and efficacy of antidiabetic drugs in maintaining optimal glycemic levels in diabetic patients. J Basic Clin Pharm.2014; 5: 79-83. https://doi.org/10.4103/0976-0105.139731

30. Ademolu BA. Sulfonylureas Induced Hypoglycemia in Diabetics - A Review. Int J Diabetes Endocrinol Special Issue: Hypoglycemia in Diabetes. 2019;.4: 109-112. https://doi.org/10.11648/j.ijde.20190404.14

31. Shriraam V, Mahadevan S, Anitharani M, Jagadeesh NS, Kurup SB, Vidya TA, et al. Reported hypoglycemia in Type 2 diabetes mellitus patients: Prevalence and practices-a hospital-based study. Indian J Endocrinol Metab 2017; 21: 148-153. https://doi.org/10.4103/2230-8210

32. Eriksson JW, Bodegard J, Nathanson D, Thuresson M, Nystro T, Norhammar A. Sulphonylurea compared to DPP-4 inhibitors in combination with metformin carries increased risk of severe hypoglycemia, cardiovascular events, and all-cause mortality. Diabetes Res Clin Pract.2016; 117: $39-4$

7. https://doi.org/10.1016/i.diabres.2016.04.05 $\underline{5}$

33. Signorovitch JE, Macaulay D, Diener M, Yan Y, Wu EQ, Gruenberger JB. Hypoglycaemia and accident risk in people with type 2 diabetes mellitus treated with non-insulin antidiabetes drugs. Diabetes Obes Metab 
2013; $\quad$ 15: 335-341.

https://doi.org/10.1111/dom.12031

34. Geller AI, Shehab N, Lovegrove MC, Kegler SR, Weidenbach KN, Ryan GJ, et al. National estimates of insulin-related hypoglycemia and errors leading to emergency department visits and hospitalisations. JAMA Intern Med
2014; $\quad$ 174: 678-686.

https://doi.org/10.1001/jamainternmed.201 $\underline{4.136}$

35. Sami W, Ansari T, Butt NS, Hamid MRA. Effect of diet on type 2 diabetes mellitus: A review. Int J Health Sci 2017; 11: 65-67. 